\title{
Stimulation of hippocampal adenylyl cyclase activity dissociates memory consolidation processes for response and place learning
}

\author{
Guillaume Martel, Annabelle Millard, ${ }^{1}$ Robert Jaffard, and Jean-Louis Guillou ${ }^{2}$ \\ Laboratoire de Neurosciences Cognitives, Université Bordeaux I, Centre Nationale de la Recherche Scientifique Unite Mixte de \\ Recherche (CNRS UMR) 5106, 33405 Talence cedex, France
}

\begin{abstract}
Procedural and declarative memory systems are postulated to interact in either a synergistic or a competitive manner, and memory consolidation appears to be a highly critical stage for this process. However, the precise cellular mechanisms subserving these interactions remain unknown. To investigate this issue, 24-h retention performances were examined in mice given post-training intrahippocampal injections of forskolin (FK) aiming at stimulating hippocampal adenylyl cyclases (ACs). The injection was given at different time points over a period of $9 \mathrm{~h}$ following acquisition in either an appetitive bar-pressing task or water-maze tasks challenging respectively "response memory" and "place memory." Retention testing $(24 \mathrm{~h})$ showed that FK injection altered memory formation only when given within a 3- to 6-h time window after acquisition but yielded opposite memory effects as a function of task demands. Retention of the spatial task was impaired, whereas retention of both the cued-response in the water maze and the rewarded bar-press response were improved. Intrahippocampal injections of FK produced an increase in PCREB immunoreactivity, which was strictly limited to the hippocampus and lasted less than 2 h, suggesting that early effects (0-2 h) of FK-induced CAMP/CREB activation can be distinguished from late effects (3-6 h). These results delineate a consolidation period during which specific cAMP levels in the hippocampus play a crucial role in enhancing memory processes mediated by other brain regions (e.g., dorsal or ventral striatum) while eliminating interference by the formation of hippocampus-dependent memory.
\end{abstract}

According to the "multiple memory systems" hypothesis, different forms of memory are organized in independent brain systems. In this context, it is now widely accepted that "declarative" forms of memory depend on hippocampal circuitry, whereas "habit," "procedural," or "response memory" depend upon a dorsal striatal system (Cohen et al. 1997). Numerous data indicate that multiple memory systems are coactivated in parallel during learning and that these systems interact (for review, see White and McDonald 2002). Converging evidence from recent human neuroimaging research and animal studies suggests that the nature of the interactions between hippocampus and dorsal striatal memory systems are either competitive (for review, see Poldrack and Packard 2003; McDonald et al. 2004a) or cooperative (Voermans et al. 2004; for review, see McDonald et al. 2004b). Despite the considerable interest in describing the cellular and molecular bases that underlie memory formation, the potential neuronal mechanisms mediating such interactions remain largely unknown. Studies have nevertheless indicated that levels of glutamate or acetylcholine release in both structures might play a crucial role (Packard 1999; McIntyre et al. 2003). Further, different types of learning have been associated with changes in the activity of particular adenylyl cyclase (AC) subtypes in a mammalian brain (for review, see Mons et al. 1999; Mons and Guillou 2004). Current data support the idea that calcium-insensitive AC isoforms may subserve different forms of memory. For instance, decreased calcium-insensitive AC activity was observed in the hippocampus after spatial learning in a wa-

'Present address: Novartis Institutes of Biomedical Research (NIBR), CH-4002 Basel, Switzerland.

${ }^{2}$ Corresponding author.

E-mail ji.guillou@Inc.u-bordeaux 1.fr; fax 33-5-4000-8743.

Article and publication are at http://www.learnmem.org/cgi/doi/10.1101/ Im.149506. ter-maze task, whereas, in contrast, an increase in this enzyme activity was found after acquisition in a procedural version of the task or in a bar-pressing task (Guillou et al. 1998, 1999a). Furthermore, the expression of the calcium-insensitive AC2 in the hippocampus was found to selectively decrease during acquisition of spatial tasks (Mons et al. 2003, 2004). Task-dependent opposite regulations of calcium-insensitive ACs strongly suggest that the particular direction of this regulation of cAMP formation within the hippocampus could reflect a mechanism enabling a selection between competing memory systems. As previously suggested, cAMP signaling deriving from calcium-insensitive ACs could have an inhibitory as opposed to a permissive action on hippocampal functioning (Guillou et al. 1999a). The aims of the present study were to investigate whether stimulation of hippocampal ACs subtypes blocks the formation of hippocampus-dependent memory and facilitates the use of memories mediated by competitive systems and, particularly, to determine at what time period during the consolidation phase that follows initial acquisition this cAMP-mediated mechanism is critical.

To investigate this issue, 24-h retention performances of mice were measured following post-training stimulation $(0-9 \mathrm{~h})$ of hippocampal ACs by intrahippocampal injections of forskolin (FK) because pharmacological tools selective for particular AC isoforms are not yet available. The injections were given after either a bar-pressing task or water-maze tasks, which challenge either striatal-dependent "response memory" or hippocampusdependent "place memory" (Packard et al. 1994; for review, see Kelley 2004). In addition, the kinetics of the phosphorylation of the cAMP-responsive element binding (CREB) was examined using an immunohistochemical technique to monitor the impact of the FK injection on cAMP-dependent neuronal activation in the brain. 


\section{Results}

\section{Post-training injections of FK improve retention in a bar-pressing task}

The rate of bar-press responses $(\mathrm{BP} / \mathrm{min})$ attained at the end of the first acquisition session $(0.83 \pm 0.07 \mathrm{BP} / \mathrm{min})$ was balanced between each group intended for each post-trial treatment $(P>0.58)$. These performances were similar independently of the post-trial delay at which the injection of artificial cerebrospinal fluid (aCSF) was given $(P>0.85)$ and, thus, all animals injected with aCSF were pooled into one group (controls). Retention performances are summarized in Figure 1. As a whole, animals displayed better performance in retention than in initial acquisition as indicated by a significant session effect $\left[F_{(1,52)}=170\right.$; $P<0.001]$. However, during the retention session, the increase in the rate of bar-press responses was significantly different between the groups [interaction group $\times$ session: $F_{(5,52)}=2.84$; $P=0.024]$. As shown in Figure 1, FK produced an improvement of the performance that was bell-shaped as a function of the post-trial delay (groups) of injection. An ANOVA conducted on these data confirmed a significant effect of delay $\left[F_{(5,52)}=3.0\right.$; $P=0.018]$. Specifically, the injection of FK given 3 or $6 \mathrm{~h}$ after acquisition, but not at earlier or later time points, significantly increased retention performance relative to controls (for both delays, $P \mathrm{~s}<0.002)$. Moreover, both of these groups immediately displayed increased levels of performance during the retention session as indicated by the time needed to perform five bar-press responses from the beginning to the end of the retention session (see Fig. 2). ANOVAs performed on these data indicated a significant effect of the repeated measures $\left[F_{(1,28)}=93.8 ; P<0.001\right]$ and a significant group effect $\left[F_{(2,28)}=4.1 ; P=0.027\right]$. Pairwise comparisons showed that the time needed to perform five bar-press responses was significantly shorter than in controls (for both FK groups, $P<0.03)$ at the beginning of the session and remained close to significance at the end of the retention session $(P<0.08)$. Finally, the activity parameter as indicated by the number of superfluous alternations between the compartments of the test box (non-operant actions) was not affected by any treatment or delay variables (all Ps $>0.13$, data not shown).

\section{Post-training injections of FK impair place memory but improve cued-response memory}

Retention performance was very similar in animals injected with aCSF either 5 min or $3 \mathrm{~h}$ following acquisition. ANOVAs confirmed these observations for the cued and spatial testing condi-

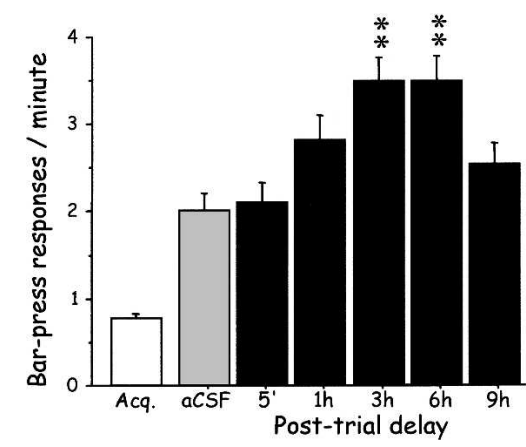

Figure 1. Effects of a bilateral intrahippocampal injection of aCSF (controls, $n=13)$ (shaded bar) or FK $(0.3 \mu \mathrm{g} / 0.2 \mu \mathrm{l})$ (solid bars) on retention performance in the bar-pressing task. Animals received FK at different delays after the acquisition (for each delay, $n=9$ ). Bar graphs represent mean $\left( \pm\right.$ SEM) number of bar-press responses per minute. ${ }^{* *}$ ) Significantly different from controls $(P<0.01)$.

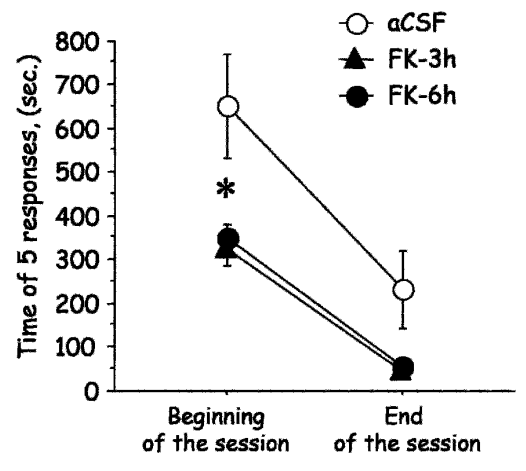

Figure 2. Effects of bilateral intrahippocampal injections of aCSF (controls, $n=13)(\bigcirc)$ or FK $(0.3 \mu \mathrm{g} / 0.2 \mu \mathrm{l})$ on the time needed to perform five bar-press responses at the beginning or at the end of the retention session. Animals received intrahippocampal injection of FK $3 \mathrm{~h}(n=9)(\boldsymbol{\Delta})$ or $6 \mathrm{~h}(n=9)(0)$ after the acquisition. Data are expressed as mean ( \pm SEM) time of 5 bar-press responses. $\left(^{*}\right)$ Significantly different from controls for both FK groups $(P<0.05)$.

tions $(P \mathrm{~s}>0.80)$ so that the two groups were pooled (control group) for subsequent statistical analysis. Results are summarized in Figure 3. Mice learned to find the escape platform faster in the cued than in the non-cued (spatial) condition. In the cued condition, decreases in both swim latencies and distances occurred within two trials, whereas eight trials were required to initiate significant spatial learning. ANOVAs conducted on these data showed a significant "trial" effect both in cued and spatial conditions [respectively, $F_{(1,27)}=42.5$ and $F_{(7,189)}=13.0 ; P \mathrm{~s}<0.001$ ].

During retention testing, controls displayed a net decrease of swim latencies in the spatial test, whereas an increase was observed with respect to acquisition in the cued testing. In contrast, an opposite pattern of retention performance was seen in mice that were given FK depending on the post-trial delay of the injection. When given 5 min after acquisition, FK did not alter retention performance in either spatial or cued conditions, whereas, when the injection was delayed by $3 \mathrm{~h}$, alterations were observed in both testing conditions. In sharp contrast to controls (and to the FK-5' group), the swim latencies recorded in the group FK-3h increased in the spatial test and remained stable in the cued testing relative to the level reached in acquisition. ANOVAs carried out on the data recorded in spatial or in cued conditions, showed a significant session $\times$ group interaction [respectively, $F_{(2,27)}=5.1 ; P=0.013$ and $F_{(2,27)}=5.2 ; P=0.012$ ]. However, post hoc comparisons indicated significant differences between FK-3H and controls (Scheffe F-test, $P=0.01$ ), or FK-5' $(P=0.03)$ for the spatial testing but not for the cued testing. Figure 4 shows swim distances recorded during both retention tests. The distances swum by mice given FK $3 \mathrm{~h}$ after the acquisition were also altered relative to controls as a function of the retention test. ANOVAs carried out on this parameter indicated a significant testing condition $\times$ group interaction $\left[F_{(2,27)}=4.9\right.$; $P=0.016]$. Post hoc comparison confirmed a significant difference between FK-3h and controls $(P=0.02)$ in the spatial testing but not in the cued testing. However, in controls, the swim distance was significantly shorter in the spatial testing than in the cued testing $(P=0.046)$, whereas a nonsignificant $(P=0.09)$ but opposite tendency (longer in the spatial testing than in the cued testing) was observed in the group for which the injection of FK was delayed $3 \mathrm{~h}$.

Finally, competition between place and cue responses during the cued testing was assessed by analyzing the number of crossings and the time spent in the virtual area where the platform was initially located for spatial learning. During this test, a large majority of mice in each group (86.7\%) first crossed the 

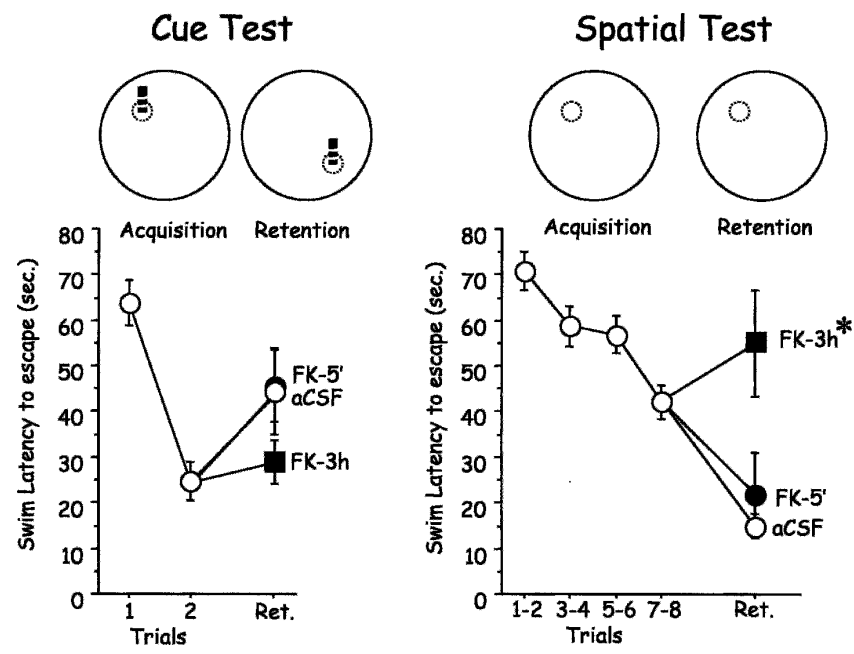

Figure 3. Effects of bilateral intrahippocampal injections of aCSF (controls, $n=10)(\bigcirc)$ or FK $(0.3 \mu \mathrm{g} / 0.2 \mu \mathrm{l})$ on cued-response memory or place memory in the water-maze task. Animals received FK $5 \min (n=10)(\bullet)$ or $3 \mathrm{~h}(n=10)(\boldsymbol{\square})$ after the acquisition. Data are expressed as mean $\left( \pm\right.$ SEM) latency to find the platform. $\left(^{*}\right)$ Significantly different from controls $(P<0.05)$.

place where the platform was initially located before reaching the cued platform as denoted by the representative swim paths shown in Figure 5A. However, FK-3h mice crossed the area where the platform was previously located less (NS, Fig. 5B) and spent less time inside the platform area $(P=0.046$, Fig. 5 C) relative to controls.

\section{FK-induced CREB phosphorylation}

Results are shown in Figure 6. Marked increases in the number of pCREB immunoreactive neurons were detected selectively in the hippocampus following FK injections. pCREB levels were about threefold higher in CA1 and CA3 subfields $30 \mathrm{~min}$ and $1 \mathrm{~h}$ than levels measured immediately after the injection of FK. In contrast, FK-induced increase of pCREB immunoreactivity was totally absent after $2 \mathrm{~h}$ or $3 \mathrm{~h}$. ANOVAs conducted on these measures indicated a significant delay effect in the CA1 $\left[F_{(4,13)}=6.63\right.$, $P=0.004]$ and in the CA3 $\left[F_{(4,13)}=4.18, P=0.02\right]$. Finally, no variation was found in structures surrounding the hippocampus as indicated in Figure 6 by pCREB levels measured in the primary somato-sensori cortex $(P>0.55)$.

\section{Discussion}

FK injection into the hippocampus induced alterations of retention performance in all testing conditions only when the injections were made between 3 and $6 \mathrm{~h}$ after the end of an acquisition session. Therefore, post-trial activations of hippocampal ACs interfere with late but not early phase of the memory consolidation process. Indeed, the kinetics of the phosphorylation of CREB observed following the injection of FK show that early effects can be temporally separated from late effects. However, global activation of hippocampal ACs by FK within this critical time window produces opposite alterations of retention performance depending on the nature of task demands; spatial memory performance was impaired whereas both cued and instrumental response memory were improved.

Earlier studies showed that intrahippocampal injections of FK, but also of dopaminergic agonists or activators of Protein Kinase A (PKA) increased 24-h retention performance in a stepdown passive avoidance task in the rat (Bernabeu et al. 1997; Bevilaqua et al. 1997). Further, these memory improvements were detected selectively following injections given 3-6 h after acquisition, that is, in correlation with the dynamics of specific learning-induced increase in cAMP concentrations, PKA activity, and CREB phosphorylation in the hippocampus as measured after the acquisition of the task (Bernabeu et al. 1997). The memory enhancement we observed in the bar-pressing task and in response to the reintroduction of the cue in our water-maze experiments also occurred selectively when FK was given within a similar time window (i.e., 3-6 $\mathrm{h}$ post-trial). In agreement with the study of Bernabeu et al. (1997), a proactive action of FK can be excluded because no effect on retention performance was found when the treatment was delayed for $9 \mathrm{~h}$ following initial acquisition. Further, as shown by its effects on phosphorylation of CREB, the efficiency of an injection of FK in the hippocampus lasts up to $1 \mathrm{~h}$ and is no longer effective after $2 \mathrm{~h}$. Thus, the kinetics of hippocampal AC activation that appear to be critical for memory formation are similar in both rats and mice. In both species, early up-regulations of cAMP pathways $(<3 \mathrm{~h})$ after acquisition do not appear to have functional consequences on memory formation despite the early changes in PKA activity or in CREB phosphorylation that have been described (Colombo 2004), whereas late up-regulations (3-6 h) seem decisive. Finally, the phosphorylation of CREB induced by the injection of FK was strictly restricted to the hippocampus. This strongly limits the possibility that diffusion of FK to any surrounding structures could have mediated its presently observed effects on memory performance.

As a whole, the improvements in retention performance we observed may be taken as an endorsement of the hypothesis according to which the cAMP-PKA pathway participates in the late phase of LTP in several regions of the hippocampus and thereby underlies memory formation (Xia and Storm 1997; Abel et al. 1998; McGaugh and Izquierdo 2000). A part of the present data showing that the injection of FK produced an opposite effect, that is, an impairment of retention performance measured in the place memory task, appears to be paradoxical with this view. However, this hypothesis was founded on results showing that calcium-stimulated isoforms of ACs are needed for hippocampus-dependent memory processing, specifically, because AC1 and AC1-AC8 double knock-out mice were shown to display long-term memory deficits in hippocampus-dependent fearconditioning and passive avoidance (Wu et al. 1995; Wong et al. 1999). Therefore, one possible interpretation for the place memory deficit we detected in our water-maze experiments is that $\mathrm{AC} 1$ and/or AC8 subtypes were in a state of overstimulation, which may have disturbed normal synaptic plasticity and interfered with the memory consolidation process. Accordingly, activation of AC activity within the hippocampus could have pro-

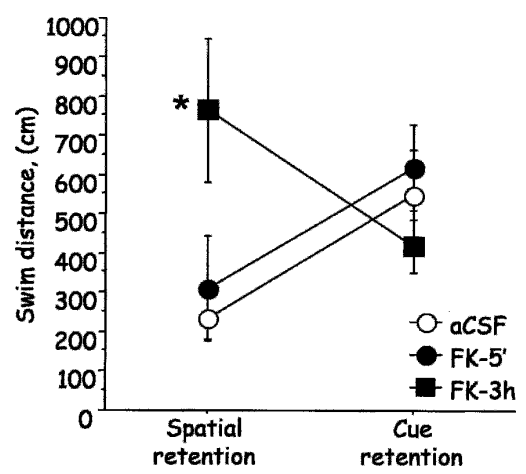

Figure 4. Swim distances during spatial retention and in the cued test for the three groups ( $n=10$ for each group). Animals received intrahippocampal injections of aCSF $(O)$ or FK $(0.3 \mu \mathrm{g} / 0.2 \mu \mathrm{l}) 5 \mathrm{~min}$ after the

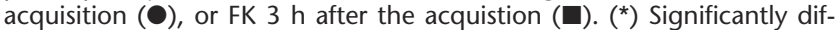
ferent from controls $(P<0.05)$.

\section{Learning \& Memory}

www.learnmem.org 
A
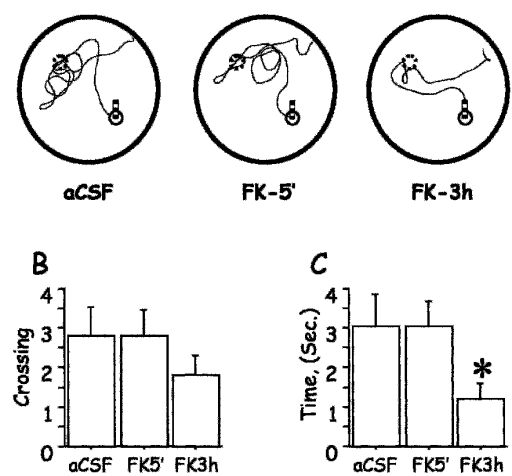

C

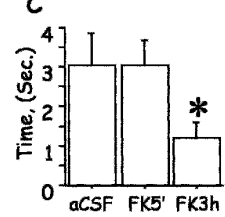

Figure 5. Effects of a bilateral intrahippocampal injection of aCSF or FK $(0.3 \mu \mathrm{g} / 0.2 \mu \mathrm{l})$ on competition between place and cue responses. (A) Representative swim paths of each group recorded during the cue test. (B) Bar graph represents mean ( \pm SEM) number of crossing over the virtual place where the platform was previously located. (C) Bar graph represents means $( \pm$ SEM) of the time spent within the virtual place area. Animals ( $n=10$ per group) received intrahippocampal injections of aCSF or FK $(0.3 \mu \mathrm{g} / 0.2 \mu \mathrm{l}) 5 \mathrm{~min}$ or $3 \mathrm{~h}$ after acquisition. (*) Significantly different from controls $(P<0.05)$.

duced a saturation of the intrinsic neuronal pathways required for long-term spatial memory formation. However, this explanation challenges other findings showing that mice with overexpression of AC1 in the forebrain display slower rates of extinction for contextual memory and increased memory for object recognition, both tasks being widely assumed to rely on an intact hippocampal system (Wang et al. 2004).

As an alternative, it is possible that the stimulation of AC subtypes other than AC1 or AC8 is responsible for the place memory deficit. In support of this possibility, other results showed that calcium-stimulated AC activity indeed increased in the hippocampus after spatial learning in a Morris water-maze task, but this occurred in parallel with a general decrease in hippocampal AC activity as assayed in the presence of the nonselective activator of AC subtypes, FK (Guillou et al. 1998, 1999a), suggesting that AC isoforms other than those stimulated by calcium must be down-regulated by spatial learning. Moreover, in situ hybridization studies showed that an increase in AC1 mRNA is preceded by a net decrease in the expression of the calciuminsensitive AC2 mRNA in all hippocampal subfields during acquisition in an Olton radial maze task (Mons et al. 2003) or in a eight-arm water-maze task (Mons et al. 2004). Thus, decrease in AC2 activity has been associated with spatial learning, and the present results suggest, therefore, that an opposition to this decrease, as produced by an injection of FK, generates a selective deficit in place memory formation. This explanation is in agreement with results showing that removal of inhibitory constraints on AC activity, such as in Gi 1 knock-out mice or following injection of pertussis toxin, dramatically impairs memory for object recognition (Pineda et al. 2004). Accordingly, a decrease in AC2 activity would be as required in combination with an increase of AC1 activity for hippocampal-dependent memory. Conversely, increases in basal and in FK-stimulated AC activity, but not in $\mathrm{Ca}^{2+}$-stimulated AC activity, was observed in mouse hippocampus following the acquisition of a procedural strategy in a bar-pressing task (Guillou et al. 1998) or in a nonspatial version of the water-maze task (Guillou et al. 1999a). Thus, an increase in $\mathrm{Ca}^{2+}$-insensitive $\mathrm{AC}$ activity has been associated with procedural learning, and the present results suggest, therefore, that potentiation of this activation, as produced by an injection of FK, promotes hippocampal-independent memory formation. The similarity of the effects (i.e., facilitation) observed in the bar-pressing task and in the cued testing performed in the water maze suggest that differences in the nature of sensory inputs or their emotional value (appetitive or aversive) are not critical variables to explain the deleterious effects produced by FK (i.e., an opposite effect) on place memory. Rather, the opposite changes produced by FK on retention performance in our water-maze tasks for which sensory inputs and motivation were comparable are likely to relate to the nature of the associations between the stimuli that are used to solve the task, that is, simple S-R association versus relational spatial associations (SSR). Changes in strategy selection have also been observed with post-training injections of glutamate (Packard 1999), following depletion of hippocampal stocks of somatostatin by cysteamine (Guillou et al. 1999b), or with hippocampal inactivation by lidocaine or bupivacaine (Packard and McGaugh 1996; Schroeder et al. 2002). It has been proposed that destroying the spatial cognitive map (O'Keefe and Nadel 1978) by lesioning or inactivating the hippocampal system, including during consolidation, may facilitate learning on tasks that require the animal to ignore spatial information (Packard et al. 1989; Matthews and Best 1995; Schroeder et al. 2002). Accordingly, in our water-maze tasks, control animals would have been biased to process space because of a functioning spatial cognitive map, whereas mice with late upregulations of some cAMP pathways would have suffered from no such bias. Nevertheless, in the operant test cage where the spatial aspect of the task is limited, it is difficult to explain enhanced bar-press responses by a removal of an interfering spatial cognitive map. The bidirectional alterations produced by intrahippocampal injection of FK also mirror the effects of hippocampal dysfunctions on memory performance as described by Eichenbaum (1994) in the relational theory. Accordingly, as in fornixlesioned mice, FK would have disrupted relational associations as required by spatial learning but improved simple associations such as those needed for response memory (Desmedt et al. 2003). Thus, stimulation of some hippocampal AC activity would have favored the selection of an S-R strategy by eliminating hippocampal-dependent relational encoding between a variety of nonrelevant stimuli that were ineluctably present in either the context of the water maze or in the operant test cage. Interestingly, a converse change in strategy selection has been described in conditional knock-out strains of mice with either a

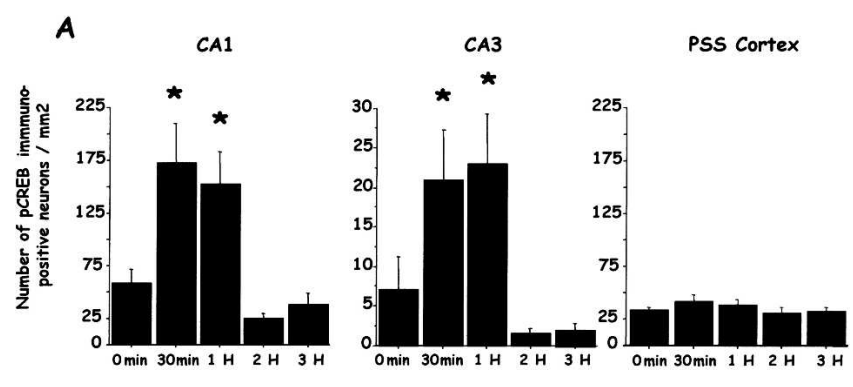

B

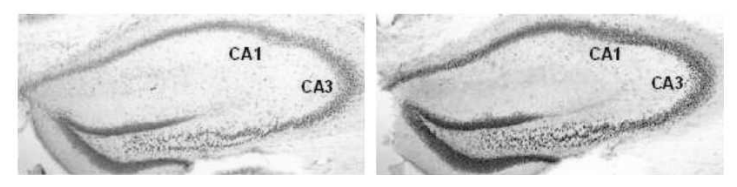

Figure 6. (A) Bar graphs represent means ( \pm SEM) of the number of pCREB positive neurons $/ \mathrm{mm}^{2}$ in the CA $1, C A 3$, or primary somato-sensori cortex (PSS cortex) at $0 \mathrm{~min}(n=2), 30 \mathrm{~min}(n=4), 1 \mathrm{~h}(n=5), 2 \mathrm{~h}$ $(n=3)$, or $3 \mathrm{~h}(n=4)$ after bilateral intrahippocampal injections of FK $(0.3 \mu \mathrm{g} / 0.2 \mu \mathrm{l}) .\left({ }^{*}\right)$ Significantly different from the group $0 \mathrm{~min}$ $(P<0.05)$. (B) Photomicrographs illustrating PCREB immunoreactivity in the dorsal hippocampus of mice injected with FK and killed either 0 min (left) or $1 \mathrm{~h}$ (right) later. 


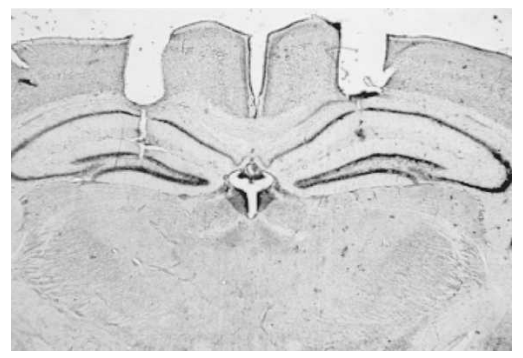

Figure 7. Histological controls showing representative placements of guide cannulae and cannulae in the dorsal hippocampus.

marked reduction or complete deletion of all CREB isoforms in the hippocampus. These subjects were markedly impaired in hippocampus-independent forms of memory whereas spatial learning was spared (Balschun et al. 2003). Along with this observation, the present data raise questions as to whether enhanced response learning is the only consequence of a removal of spatial mapping or relational processing or whether a specific hippocampal functioning involving intrinsic regulation of a cAMP/PKA/CREB pathway controls the selection of learning strategies.

The present results delineate a critical time window during which both improvements in response memory and deficits in place memory are selectively produced by a positive regulation on hippocampal AC activity. This indeed suggests that a bidirectional regulation of cAMP pathways could have a pivotal role in this late phase (3-6 h post-training) of memory formation and, further, that the direction of the regulation of hippocampal cAMP levels produced by calcium-insensitive AC isoforms, such as possibly AC2 (Mons et al. 2003), in the late phase of consolidation processing would be determinant in selecting which particular memory system will be used as a function of the cognitive demand involved, that is, as a function of the configuration of the stimuli that were relevant to solve the task.

\section{Conclusions}

The present findings corroborate the concept that multiple memory systems interact in a competitive manner in a mammalian brain (White and McDonald 2002) and strongly support the view that the hippocampus plays a crucial role in these interactions (Jaffard and Meunier 1993) by involving complex regulations of various sources of cAMP formation. Furthermore, they suggest that consolidation is a highly flexible process that not only regulates the strength or the weakness of memory traces but also determines how, and in which neuronal networks, a particular form of memory is generated in adaptation to the situation in which the subject is engaged.

\section{Materials and Methods}

\section{Animals}

Male mice $(n=108)$ of the C57BL/6ByJIco strain (IFFA CREDO Lyon, France) were used. Animals were received in the laboratory at $6 \mathrm{wk}$ of age and were housed collectively in an animal room equipped with air-conditioning $\left(23^{\circ} \mathrm{C}\right)$ and with an artificial light/dark cycle of $12 \mathrm{~h}$ (7:00 a.m. on). At the age of 3-4 mo (25-30 g), mice were housed in individual cages and were given ad libitum access to food and water for $10 \mathrm{~d}$ before surgery. During the recovery period, they were handled ( $3 \mathrm{~min}$ per day) and weighed daily for $10 \mathrm{~d}$. For the bar-pressing task, the food ration was adjusted individually so that all mice had reached $82 \%$ of their ad libitum weights at the beginning of the experiments.

Experiments were performed in accordance with the European Communities Council Directive of 24 November 1986 (86/ 609/EEC).

\section{Intrahippocampal injections}

\section{Surgery}

Mice were implanted under general anesthesia (Avertin, $300 \mathrm{mg} /$ $\mathrm{kg}$ i.p.) with two guide cannulae $(0.4 \mathrm{~mm}$ diameter, $8 \mathrm{~mm}$ long) aimed vertically toward the dorsal hippocampus. Guide cannulae were fixed to the skull bone with dental cement and fine bone screws. Stereotaxic coordinates were $2.0 \mathrm{~mm}$ posterior to the bregma, $1.3 \mathrm{~mm}$ each side of the sagittal suture, $0.9 \mathrm{~mm}$ ventral from the skull surface. Following surgery, the mice remained in the animal room for a recovery period of $10 \mathrm{~d}$ before the experimental phase began. At the end of the experiments, mice were killed and placements of guide cannulae were verified histologically as being correctly located above the dorsal hippocampus (see Figure 7).

\section{Drug injections}

Bilateral intrahippocampal injections of vehicle (aCSF, $0.2 \mu \mathrm{l} /$ hippocampus) or 7b-diacetyl-7b-(g-N-methylpiperazino)-butyril, dihydrochloride (i.e., FK, Calbiochem, France) at the dose of $0.3 \mu \mathrm{g} / 0.2 \mu \mathrm{l}(2.4 \mathrm{mM}$ ) based on previous studies (Wong et al. 1999). Injections were performed in freely moving mice via injection cannulae $(0.2 \mathrm{~mm}$ diameter, $9 \mathrm{~mm}$ long) attached to $1-\mu \mathrm{l}$ Hamilton syringes via polyethylene catheter tubing. The syringes were held in a constant-rate infusion pump and injection was conducted over a 3-min period. In all cases, correct injection flow rates were visually controlled. The cannulae were left in place for a further $2 \mathrm{~min}$ before removal. aCSF contains $5 \mathrm{mM}$ glucose, $125 \mathrm{mM}$ sodium chloride, $27 \mathrm{mM}$ sodium hydrogen carbonate, $2.5 \mathrm{mM}$ potassium chloride, $0.5 \mathrm{mM}$ sodium dihydrogen phosphate-hydrate, $1.2 \mathrm{mM} 2$-sodium hydrogen phosphate, and phosphoric acid to $\mathrm{pH} 7.4$.

\section{Bar-pressing task}

\section{Apparatus}

Behavioral testing was carried out in an operant test cage $(12.5 \times 13.5 \times 18.5 \mathrm{~cm})$ based on that described by Destrade et al. (1973) and made of translucent Plexiglas with a metal grid floor. A metal bar $(5.8 \times 3 \mathrm{~cm})$ and a food cup extended from one wall and were separated by a $5-\mathrm{cm}$ partition so that, after a bar-press, the mouse had to circumnavigate the partition to reach the food cup. The cage was equipped with photoelectric cells that detected the position of the animal in front of the bar and the food cup. This information was constantly transmitted to a computer, allowing automatic recording of each bar-press and consumption of the reinforcers. The test cage controls were programmed for continuous reinforcement (CRF1). An operant response was defined as a bar-press followed within $30 \mathrm{sec}$ by the consumption of a miniature $(4 \mathrm{mg})$ decorticated seed of millet.

\section{Behavioral procedure}

For the acquisition session, the mouse was placed into the test cage and was allowed to perform 15 operant responses. Then, a post-trial injection of aCSF or FK was given either 5 min, 1, 3, 6, or $9 \mathrm{~h}$ after the end of the acquisition session. The next day ( 24 $\mathrm{h}$ later) the mouse was replaced in the test-cage and retention performance was measured during $30 \mathrm{~min}$. Previous studies showed that the frequency of operant responses does not, or only slightly, increases over 15 trials, so that the acquisition of the task is only partial in control mice at the end of the first training session. However, performance in the 24-h retention test shows that mice have associated, by that time, the pressing on the lever with the release of a pellet into the food cup and organize a motor pattern to collect food pellets as rapidly as possible (Destrade and Cardo 1974; Jaffard et al. 1974). For each session, the number of operant responses over blocks of 5-min periods was recorded and analyzed with two-factor ANOVAs. The general motor activity of the mice was monitored by counting the number of alternations between the two compartments of the test cage that were performed without any operant actions (bar press or food intake). 


\section{Water-maze tasks}

\section{Apparatus}

The training apparatus was a circular pool (1.5 $\mathrm{m}$ diameter) filled with water that was heated to $22^{\circ} \mathrm{C}$ and rendered opaque by the addition of white Color Prima (Pebeo, France), a nontoxic latex paint. The pool was surrounded by numerous visual cues, which were kept in constant locations during the entire training period. A circular escape platform $(13 \mathrm{~cm}$ diameter) was submerged $\sim 0.8 \mathrm{~cm}$ below the surface of the water. The escape platform was placed in the center of one of four imaginary quadrants of the pool and kept in this location throughout acquisition. For cued testing, a cylinder $(15 \mathrm{~cm}$ high $\times 3 \mathrm{~cm}$ diameter $)$ with blackwhite striped patterns was positioned on the platform center. Swim times and distances were recorded and analyzed using an automated tracking system (Videotrack, Champagne au Mont d'Or, France). Between trials, the mice were dried and kept warm in a box equipped with dark lamps (night club lamps) providing an ambient temperature of $30^{\circ} \mathrm{C}$ inside the box.

\section{Behavioral procedures}

The test used was an adaptation of the procedure previously described by McDonald and White (1994). For acquisition, all mice were given ten trials, with an intertrial interval of $10 \mathrm{~min}$. For each trial, the mouse was placed into the pool (facing the wall) from one of four randomly varied start positions (N, S, W, E) located around the rim of the pool and was then allowed a maximum of $90 \mathrm{sec}$ to find the escape platform (NW). If the mouse found the platform, it was allowed to rest on it for $20 \mathrm{sec}$ before being removed from the pool and placed back into its home cage (inside the warming box). If a mouse did not locate the platform within $90 \mathrm{sec}$, the animal was hand guided to it. Acquisition started with the black-white cylinder placed on the escape platform for two trials. Then, the cylinder was removed and the mice performed eight trials with extra-maze indications only (i.e., spatial learning). A post-trial injection of aCSF or FK was given either $5 \mathrm{~min}$ or $3 \mathrm{~h}$ after the acquisition session. The next day ( $24 \mathrm{~h}$ later), retention for place or cue responses was tested. First, the invisible platform was kept in the same location as in acquisition (NW) for the spatial test. Then, the platform was moved to the opposite quadrant (i.e., SE) and the cylinder was installed on it for the cued test. The start positions used for the cued test were randomly NE and SW to equilibrate distances to respond to the cue or the place (i.e., as defined by the area where the platform was initially located). Swim latencies and distances to reach the escape platform were recorded and analyzed using one- or twoway ANOVAs.

\section{Immunohistochemical analysis of phosphorylated CREB (pCREB)}

\section{Procedure}

An additional group of naive animals were each given an intrahippocampal injection of FK and were deeply anaesthetized with $300 \mathrm{mg} / \mathrm{kg}$ avertin either $0 \mathrm{~min}, 30 \mathrm{~min}, 1 \mathrm{~h}, 2 \mathrm{~h}$, or $3 \mathrm{~h}$ later. Then, they were immediately perfused transcardially with icecold solutions of $4 \%$ paraformaldehyde in phosphate buffer $(0.1$ $\mathrm{M}, \mathrm{pH}$ 7.4). After post-fixation overnight in the same fixative at $4^{\circ} \mathrm{C}$, coronal sections $(40 \mu \mathrm{m})$ were cut on a vibratome (Leica) and collected in Tris Buffer. After elimination of endogenous peroxidase activity and a preincubation step, sections were incubated for $48 \mathrm{~h}$ with rabbit anti-pCREB antibody (1:3000 dilution; Euromedex France). Subsequently, sections were incubated with biotinylated goat anti-rabbit antibody (1:2000; Vector ABC kit) and with the $\mathrm{ABC}$ complex (Vector $\mathrm{ABC}$ kit) before being reacted with diaminobenzidine (DAB). Sections were mounted on gelatin-coated slides, air-dried, dehydrated, covered with a coverslip with Eukitt, and examined using light microscopy.

\section{Quantification and analysis}

The number of pCREB positive cells was counted in the hippocampus (CA1 and CA3) and surrounding structures such as the posterior parietal association area or the primary somato-sensori cortex using a computerized image processing system coupled to an optical microscope (Visiolab2000, Biocom, Lyon, France). Counting was performed at a $\times 10$ magnification. The anteroposterior (AP) coordinates relative to bregma of the areas included for detailed analyses were AP -1.4 to $-2.4 \mathrm{~mm}$ (atlas of Franklin and Paxinos 1996). Nuclei were counted and expressed as the number of pCREB positive nuclei per $\mathrm{mm}^{2}$. Statistical analysis of immunohistochemical data was performed using ANOVA.

\section{Acknowledgments}

This study was supported by the Centre National de la Recherche Scientifique. We thank Dr. Thomas Durkin and Helen Turner for helpful comments on the manuscript and Dr. Nicole Mons for her helpful assistance with the immunohistochemical experiments.

\section{References}

Abel, T., Martin, K.C., Bartsch, D., and Kandel, E.R. 1998. Memory suppressor genes: Inhibitory constraints on the storage of long-term memory. Science 279: 338-341.

Balschun, D., Wolfer, D.P., Gass, P., Mantamadiotis, T., Welzl, H., Schutz, G., Frey, J.U., and Lipp, H.P. 2003. Does cAMP response element-binding protein have a pivotal role in hippocampal synaptic plasticity and hippocampus-dependent memory? J. Neurosci. 23: 6304-6314.

Bernabeu, R., Bevilaqua, L., Ardenghi, P., Bromberg, E., Schmitz, P., Bianchin, M., Izquierdo, I., and Medina, J.H. 1997. Involvement of hippocampal cAMP/cAMP-dependent protein kinase signaling pathways in a late memory consolidation phase of aversively motivated learning in rats. Proc. Natl. Acad. Sci. 94: 7041-7046.

Bevilaqua, L., Ardenghi, P., Schroder, N., Bromberg, E., Quevedo, J., Schmitz, P.K., Bianchin, M., Walz, R., Schaeffer, E., Medina, J.H., et al. 1997. Agents that affect cAMP levels or protein kinase A activity modulate memory consolidation when injected into rat hippocampus but not amygdala. Braz. J. Med. Biol. Res. 30: 967-970.

Cohen, N.J., Poldrack, R.A., and Eichenbaum, H. 1997. Memory for items and memory for relations in the procedural/declarative memory framework. Memory 5: 131-178.

Colombo, P.J. 2004. Learning-induced activation of transcription factors among multiple memory systems. Neurobiol. Learn. Mem. 82: 268277.

Desmedt, A., Marighetto, A., Garcia, R., and Jaffard, R. 2003. The effects of ibotenic hippocampal lesions on discriminative fear conditioning to context in mice: Impairment or facilitation depending on the associative value of a phasic explicit cue. Eur. J. Neurosci. 17: 19531963.

Destrade, C. and Cardo, B. 1974. Effects of post-trial hippocampal stimulation on time-dependent improvement of performance in mice. Brain Res. 78: 447-454.

Destrade, C., Soumireu Mourat, B., and Cardo, B. 1973. Effects of posttrial hippocampal stimulation on acquisition of operant behavior in the mouse. Behav. Biol. 8: 713-724.

Eichenbaum, H. 1994. The hippocampal system and declarative memory in humans and animals: Experimental analysis and historical origins. In Memory Systems (eds. D.L. Schacter and E. Tulving), pp. 147-201. The MIT Press, Cambridge, MA.

Franklin, K.B. and Paxinos, G. 1996. The mouse brain in stereotaxic coordinates. Academic Press, San Diego, CA.

Guillou, J.L., Micheau, J., and Jaffard, R. 1998. The opposite effects of cysteamine on the acquisition of two different tasks in mice are associated with bidirectional testing-induced changes in hippocampal adenylyl cyclase activity. Behav. Neurosci. 112: 900-908.

Guillou, J.L., Rose, G.M., and Cooper, D.M. 1999a. Differential activation of adenylyl cyclases by spatial and procedural learning. J. Neurosci. 19: 6183-6190.

Guillou, J.L., Micheau, J., and Jaffard, R. 1999b. Intrahippocampal injections of cysteamine improve the retention of a bar-pressing task in mice. Behav. Brain Res. 103: 113-117.

Jaffard, R. and Meunier, M. 1993. Role of the hippocampal formation in learning and memory. Hippocampus 3 Spec No: 203-217.

Jaffard, R., Destrade, C., Soumireu-Moral, B., and Cardo, B. 1974. Time-dependent improvement of performance on appetitive tasks in mice. Behav. Biol. 11: 89-100.

Kelley, A.E. 2004. Memory and addiction: Shared neural circuitry and molecular mechanism. Neuron 44: 161-179.

Matthews, D.B. and Best, P.J. 1995. Fimbria/fornix lesions facilitate the 
learning of nonspatial response task. Psychon. Bull. Rev. 2: 113-116. McDonald, R.J. and White, N.M. 1994. Parallel information processing in the water maze: Evidence for independent memory systems involving dorsal striatum and hippocampus. Behav. Neural Biol. 61: $260-270$.

McDonald, R.J., Hong, N.S., and Devan, B.D. 2004a. The challenges of understanding mammalian cognition and memory-based behaviours: An interactive learning and memory systems approach. Neurosci. Biobehav. Rev. 28: 719-745.

McDonald, R.J., Devan, B.D., and Hong, N.S. 2004b. Multiple memory systems: Tthe power of the interactions. Neurobiol. Learn. Mem. 82: $333-346$.

McGaugh, J.L. and Izquierdo, I. 2000. The contribution of pharmacology to research on the mechanisms of memory formation. Trends Pharmacol. Sci. 21: 208-210.

McIntyre, C.K., Marriott, L.K., and Gold, P.E. 2003. Patterns of brain acetylcholine release predict individual differences in preferred learning strategies in rats. Neurobiol. Learn. Mem. 79: 177-183.

Mons, N. and Guillou, J.L. 2004. Adenylyl cyclases. In Memories are made of these: From messengers to molecules (eds. G. Riedel and B. Platt), pp. 330-348. Landes Bioscience, Georgetown, TX.

Mons, N., Guillou, J.L., and Jaffard, R. 1999. The role of $\mathrm{Ca}^{2+} /$ calmodulin-stimulable adenylyl cyclases as molecular coincidence detectors in memory formation. Cell. Mol. Life Sci. 55: $525-533$.

Mons, N., Guillou, J.L., Decorte, L., and Jaffard, R. 2003. Spatial learning induces differential changes in calcium/calmodulin-stimulated (ACI) and calcium-insensitive (ACII) adenylyl cyclases in the mouse hippocampus. Neurobiol. Learn. Mem. 79: 226-235.

Mons, N., Segu, L., Nogues, X., and Buhot, M.C. 2004. Effects of age and spatial learning on adenylyl cyclase mRNA expression in the mouse hippocampus. Neurobiol. Aging 25: 1095-1106.

O'Keefe, J. and Nadel, L. 1978. The hippocampus as a cognitive map. Oxford University Press, Oxford, UK.

Packard, M.G. 1999. Glutamate infused posttraining into the hippocampus or caudate-putamen differentially strengthens place and response learning. Proc. Natl. Acad. Sci. 96: 12881-12886.

Packard, M.G. and McGaugh, J.L. 1996. Inactivation of hippocampus or caudate nucleus with lidocaine differentially affects expression of place and response learning. Neurobiol. Learn. Mem. 65: 65-72.

Packard, M.G., Hirsh, R., and White, N.M. 1989. Differential effects of fornix and caudate nucleus lesions on two radial maze tasks: Evidence for multiple memory systems. J. Neurosci. 9: 1465-1472.

Packard, M.G., Cahill, L., and McGaugh, J.L. 1994. Amygdala modulation of hippocampal-dependent and caudate nucleus-dependent memory processes. Proc. Natl. Acad. Sci. 91: 8477-8481.

Pineda, V.V., Athos, J.I., Wang, H., Celver, J., Ippolito, D., Boulay, G., Birnbaumer, L., and Storm, D.R. 2004. Removal of $\mathrm{G}_{\mathrm{i} \alpha 1}$ constraints on adenylyl cyclase in the hippocampus enhances LTP and impairs memory formation. Neuron 41: 153-163.

Poldrack, R.A. and Packard, M.G. 2003. Competition among multiple memory systems: Converging evidence from animal and human brain studies. Neuropsychologia 41: 245-251.

Schroeder, J.P., Wingard, J.C., and Packard, M.G. 2002. Post-training reversible inactivation of hippocampus reveals interference between memory systems. Hippocampus 12: 280-284.

Voermans, N.C., Magnus Petersson, K., Daudey, L., Weber, B., Van Spaendonck, K.P., Kremer, H.P.H., and Fernández, G. 2004. Interaction between the human hippocampus and the caudate nucleus during route recognition. Neuron 43: 427-435.

Wang, H., Ferguson, G.D., Pineda, V.V., Cundiff, P.E., and Storm, D.R. 2004. Overexpression of type-1 adenylyl cyclase in mouse forebrain enhances recognition memory and LTP. Nat. Neurosci. 7: 635-642.

White, N.M. and McDonald, R.J. 2002. Multiple parallel memory systems in the brain of the rat. Neurobiol. Learn. Mem. 77: 125184.

Wong, S.T., Athos, J., Figueroa, X.A., Pineda, V.V., Schaefer, M.L., Chavkin, C.C., Muglia, L.J., and Storm, D.R. 1999.

Calcium-stimulated adenylyl cyclase activity is critical for hippocampus-dependent long-term memory and late phase LTP. Neuron 23: 787-798.

Wu, Z.L., Thomas, S.A., Villacres, E.C., Xia, Z., Simmons, M.L., Chavkin, C., Palmiter, R.D., and Storm, D.R. 1995. Altered behavior and long-term potentiation in type I adenylyl cyclase mutant mice. Proc. Natl. Acad. Sci. 92: 220-224.

Xia, Z. and Storm, D.R. 1997. Calmodulin-regulated adenylyl cyclases and neuromodulation. Curr. Opin. Neurobiol. 7: 391-396.

Received November 25, 2005; accepted in revised form February 21, 2006.

348 Learning \& Memory

www.learnmem.org 


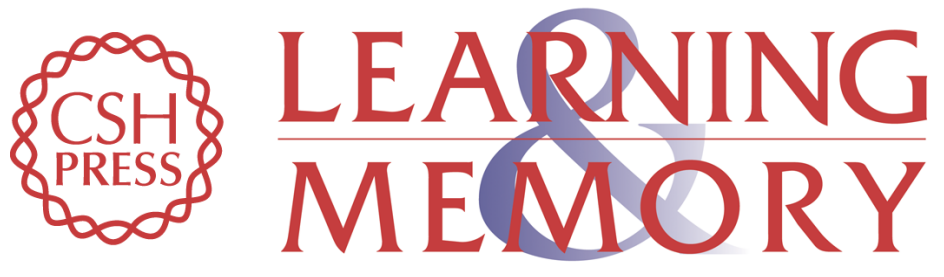

\section{Stimulation of hippocampal adenylyl cyclase activity dissociates memory consolidation processes for response and place learning}

Guillaume Martel, Annabelle Millard, Robert Jaffard, et al.

Learn. Mem. 2006, 13:

Access the most recent version at doi:10.1101//m.149506

References This article cites 35 articles, 8 of which can be accessed free at:

http://learnmem.cshlp.org/content/13/3/342.full.html\#ref-list-1

License

Email Alerting Receive free email alerts when new articles cite this article - sign up in the box at the Service top right corner of the article or click here. 